\title{
CHEMICAL PROFILES OF ESSENTIAL OILS AND FATTY ACIDS FROM Erythrina velutina
}

\author{
Margareth G. Teixeira ${ }^{a}$, Marcílio M. de Moraes ${ }^{\mathrm{a}}$ and Claudio A. G. da Camara*,a, \\ aDepartamento de Química, Universidade Federal Rural de Pernambuco, 52171-030 Recife - PE, Brasil
}

Recebido em 11/07/2018; aceito em 24/10/2018; publicado na web em 07/11/2018

\begin{abstract}
Chemical analysis involving gas chromatography coupled to mass spectrometry of the essential oils of red and orange flowers from E. velutina revealed a predominance of phenylpropanoids in both samples. However, qualitative and quantitative differences were found in the compositions. $(E)$-Asarone $(16.22 \pm 0.23 \%)$ and $(E)$-caryophyllene $(12.22 \pm 0.11 \%)$ were identified as the major constituents of the essential oil from the red flowers, whereas $(E)$-caryophyllene $(41.72 \pm 1.65 \%)$ and eugenol $(20.99 \pm 0.21 \%)$ were identified as the major constituents of the oil from the orange flowers. Seventeen fatty acids were characterized in the red and black seeds. The fatty acid composition in the two chromatic variations had a high degree of similarity. Oleic acid $(41.56 \pm 1.33 \%$ and $46.12 \pm 1.90 \%$ in the red and black seeds, respectively), palmitic acid $(15.39 \pm 0.16 \%$ and $12.33 \pm 0.41 \%)$ and behenic acid $(9.95 \pm 0.14 \%$ and $12.10 \pm 0.42 \%)$ were identified as the main fatty acids. Principal component analysis (PCA) and hierarchical cluster analysis (HCA) enabled identifying significant differences in the chemical profile of the essential oils from the red flower and orange flower varieties of E. velutina. In contrast, PCA and HCA analysis revealed no significant differences in the fatty acid profile of the red and black seeds.
\end{abstract}

Keywords: Erythrina velutina; fatty acids; essential oil; chemical constituents.

\section{INTRODUCTION}

The genus Erythrina (Fabaceae) has broad distribution in tropical and subtropical regions and is composed of 120 species, 70 of which are found in the Americas. ${ }^{1}$ Eleven species of the genus occur in Brazil. ${ }^{2}$ Erythrina velutina is particularly abundant in the state of Pernambuco, occurring on both the mainland and the island of Fernando de Noronha. Known locally as "mulungu", E. velutina is a large arboreal plant with a twisted stem that is employed for landscaping purposes and the regeneration of degraded areas. In folk medicine, the infusion of the bark is indicated as a tranquilizer and cough suppressant as well as for the treatment of bronchitis, hemorrhoids and parasitic intestinal infections. ${ }^{3,4}$

The flowers of E. velutina are predominantly red, with some plants exhibiting orange flowers. However, other plants, especially cultivated ones, have different colors, such as greenish yellow, white or pale. ${ }^{5}$ The fruit is a dehiscent legume, with a pod measuring 5 to 8 $\mathrm{cm}$ in length containing one to three kidney-shaped, shiny red seeds. ${ }^{6}$ Ridley $^{7}$ identified a plant found on the island of Fernando de Noronha with the same morphological characteristics as E. velutina, but with chromatic differences in the seeds as a new species denominated E. aurantiaca (black or blackish red seeds). In the mid $20^{\text {th }}$ century, Krukoff ${ }^{8}$ noted that the species Ridley identified had many similarities to E. velutina, with a difference only in the color of the seeds. As E. aurantiaca had blackish red or black seeds and E. velutina had red seeds, Krukoff proposed a new combination: E. velutina fo. aurantiaca. Recently, genetic studies of individuals with red and black or blackish red seeds collected on the island of Fernando de Noronha demonstrated similarities and proposed the synonymy of the aurantiaca form of Erythrina velutina. ${ }^{9}$ Specimens with orange flowers and black or blackish red seeds only occur on the island of Fernando de Noronha. According to a bibliographic survey, chemical investigations of E. velutina (red seeds) collected on the mainland reveal the presence of alkaloids and flavonoids. ${ }^{10,11}$ However, no previous study has been conducted for the identification of the chemical constituents of the essential oils from this species.

*e-mail: claudio_agc@hotmail.com
In our ongoing efforts to broaden knowledge on the chemical profiles of plants that occur in the state of Pernambuco (northeastern Brazil), the aim of the present study was to determine and compare the chemical composition of the essential oils from the flowers and fatty acids from the seeds of E. veluntina that occur on the island of Fernando de Noronha and have chromatic differences in the seeds and flowers.

\section{MATERIAL AND METHODS}

\section{Collection of plant material}

The flowers and seeds of each synonym of Erythrina velutina Willd. were collected from five specimens from different sites (light orange flower and black seeds: Forte de Nossa Senhora dos Remédios 32 24'37' W 350'22" S; Praia da Conceição 32 25'08' W

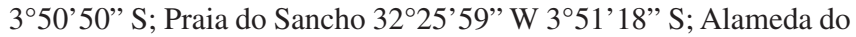

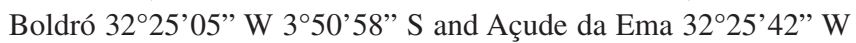
$3^{\circ} 51^{\prime} 01$ " S; red flowers and red seeds: Forte de Nossa Senhora dos

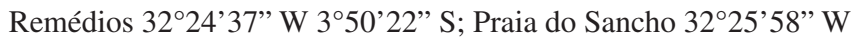
$3^{\circ} 51^{\prime} 18^{\prime \prime} \mathrm{S}$ and $32^{\circ} 25^{\prime} 59^{\prime \prime} \mathrm{W} 3^{\circ} 51^{\prime} 18^{\prime \prime} \mathrm{S}$; Alameda do Boldró

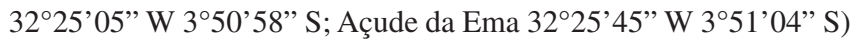
on the Fernando de Noronha archipelago in the state of Pernambuco - Brazil. The plants were identified by botanist M. R. Pereira (Federal Rural University of Pernambuco). Voucher of both samples were mounted and deposited in the Vasconcelos Sobrinho Herbarium of the same university (UFRPE) under numbers: 19951 Erythrina velutina (red seed) and 49645 E. velutina (black seed).

\section{Chemicals}

All monoterpenes ( $\alpha$-pinene; $\beta$-pinene; myrcene; limonene; terpinolene; camphor; $\alpha$-terpineol; carvacrol), sesquiterpenes ((E)-caryophyllene; caryophyllene oxide), phenilpropanoids (eugenol; eugenol acetate; $(E)$-asarone; $(Z)$-asarone; apiole) and methyl esters (methyl myristate (C14:0), methyl palmitate (C16:0) and methyl stearate (C18:0)) were purchased from Sigma-Aldrich Brazil (> 98\%). 
HPLC-grade methanol and hexane were purchased from Merck SA and used without further purification. Hydrochloric acid (36\%), anhydrous sodium sulfate $\left(\mathrm{Na}_{2} \mathrm{SO}_{4}\right)$ and potassium hydroxide $(\mathrm{KOH}$, $>85 \%$ ) were purchased from Sigma-Aldrich - Brazil. Deionized water was purified by a Milli-Q purification system (Millipore, Bedford, MA, USA).

\section{Isolation of essential oils}

The essential oils from fresh red and orange flowers $(200 \mathrm{~g})$ were separately isolated using a modified Clevenger-type apparatus and hydrodistillation for $2 \mathrm{~h}$. The oil layers were separated and dried over anhydrous sodium sulfate and stored in hermetically sealed glass containers at a low temperature $\left(-5^{\circ} \mathrm{C}\right)$ until analysis. Total oil yields were expressed as percentages ( $\mathrm{g} / 100 \mathrm{~g}$ of fresh plant material). All experiments were carried out in triplicate.

\section{Preparation of fatty acid methyl esters from seed oil}

Approximately $50 \mathrm{~g}$ of E. velutina black and red seeds were milled and extracted separately with n-hexane in a Soxhlet apparatus. The residual solvent in the oil was evaporated and the oil yield was determined in relation to the dry mass of the original sample. The oils from the black and red E. velutina seeds were converted into methyl esters using the transesterification process in methanol with a basic catalyst. The dried oils reacted with the catalyst (potassium hydroxide) dissolved in methanol for $45 \mathrm{~min}$ at $45{ }^{\circ} \mathrm{C} .{ }^{12} \mathrm{~A}$ solution of hydrochloric acid was added, followed by water until reaching $\mathrm{pH}$ 7. The methyl esters were extracted three times with n-hexane. The organic phases were united and the solvent was removed with a rotary evaporator. An aliquot corresponding to about $0.1 \mathrm{mg}$ was diluted in $1 \mathrm{~mL}$ of $n$-hexane and analyzed by gas chromatography coupled to mass spectrometry (GC-MS) to determine the fatty acid composition.

\section{Gas chromatography}

Quantitative GC analyses were carried out using a HewlettPackard 5890 Series II GC apparatus equipped with a flame ionization detector (FID) and a non-polar DB-5 fused silica capillary column (30 $\mathrm{m} \times 0.25 \mathrm{~mm} \times 0.25 \mu \mathrm{m})(\mathrm{J} \& \mathrm{~W}$ Scientific). The oven temperature was programmed from 60 to $240{ }^{\circ} \mathrm{C}$ and held for $6 \mathrm{~min}$ at a rate $3{ }^{\circ} \mathrm{C}$ $\mathrm{min}^{-1}$. Injector and detector temperatures were $260^{\circ} \mathrm{C}$. Hydrogen was the carrier gas, with a flow rate of $1 \mathrm{~mL} \mathrm{~min}^{-1}$ in split mode (1:30). The injection volume was $0.5 \mu \mathrm{L}$ of diluted solution (1/100) of oil in $n$-hexane. The amount of each compound was calculated from GC peak areas in the order of the DB-5 column elution and expressed as a relative percentage of the area of the chromatograms. All analyses were carried out in triplicate.

\section{Gas chromatography-mass spectrometry}

The GC-MS analysis was carried out using a Varian 220-MS IT GC system with a mass selective detector mass spectrometer in EI 70 $\mathrm{eV}$ with a scan interval of $0.5 \mathrm{~s}$ and fragments from 40 to $550 \mathrm{Da}$ fitted with the same column and temperature program as that for the GC experiments. Helium was the carrier gas, with a flow rate of $1 \mathrm{~mL} \mathrm{~min}^{-1}$ in split mode (1:30). The injection volume was $1 \mu \mathrm{L}$ of diluted solutions $(1 / 100)$ of oil in $n$-hexane. All analyses were carried out in triplicate.

\section{Identification of components}

The identification of the components was based on GC retention indices with reference to a homologous series of $\mathrm{C}_{8}-\mathrm{C}_{40} \mathrm{n}$-alkanes calculated using the Van den Dool and Kratz equation ${ }^{13}$ by computer matching against the mass spectral library of the GC-MS databases, such as the NIST electron ionization (EI) mass spectral library, ${ }^{14}$ and co-injection with authentic standards as well as other published mass spectra. ${ }^{15}$ Area percentages were obtained from the GC-FID response without the use of an internal standard or correction factors.

\section{Statistical analysis}

Based on the results of chromatographic analysis of fatty acids in the red and black Erythrina velutina seeds as well as previous reports on other species of Erythrina (E. variegate, E. velutina, E. lithosperna, E. arborescens, E. stricta, E. indica 1, E. indica 2, E. indica 3, E. speciosa, E. suberosa and E. Americana) ${ }^{16}$ a species similarity graph was generated by the distance of the correlation coefficient using hierarchical cluster analysis (HCA) with the aid of BioDiversity Pro version 2. ${ }^{17}$ Principal component analysis (PCA) based on the complete dataset was conducted to evaluate the fatty acid composition of the Erythrina seeds. GC-MS data were exported in ASCII format to Microsoft Excel to produce a data matrix of sample versus metabolite peaks with associated peak areas. All the analyses were performed using Unscrambler ${ }^{\circledR}$ version 9.5. ${ }^{18}$

\section{RESULTS AND DISCUSSION}

Hyrdodistillation of the red and orange flowers from the varieties of E. velutina that occur on the island of Fernando de Noronha furnished yellow and colorless essential oils, respectively. Table 1 displays the yields, specific rotation and identification of the chemical constituents of the two essential oils. A greater yield was achieved with the orange variety $(0.07 \pm 0.00 \%)$. The oils were levorotatory, with a specific rotation of $[\alpha]_{\mathrm{D}}^{25}=-27.4^{\circ}\left(\mathrm{c}=1, \mathrm{CH}_{2} \mathrm{Cl}_{2}\right)$ for the oil from the red flowers and $[\alpha]_{\mathrm{D}}^{25}=-18.0^{\circ}\left(\mathrm{c}=1, \mathrm{CH}_{2} \mathrm{Cl}_{2}\right)$ for the oil from the orange flowers.

The GC-MS analysis enabled the identification of 64 compounds, representing $94.67 \pm 0.81 \%$ and $95.97 \pm 1.93 \%$ of the oils from the red and orange flowers, respectively (oil chromatograms in Figure 1S, Supplementary Material). Both oils are characterized by ketones, alcohols, esters, fatty acids, monoterpenes, sesquiterpenes and phenylpropanoids.

Forty-seven compounds were identified in the essential oil from the red flowers, in which phenylpropanoids constituted the predominant chemical class $(47.42 \pm 0.71 \%)$. (E)-Asarone $(16.22 \pm 0.23 \%)$ was the major constituent, followed by $(E)$-caryophyllene $(12.22 \pm 0.11 \%)$ and exalatacin $(9.94 \pm 0.20 \%)$. Significant percentages of other constituents were also identified, such as eugenol $(6.05 \pm 0.64 \%)$, $\gamma$-terpinene $(5.19 \pm 0.41 \%)$ and $(Z)$-asarone $(5.99 \pm 0.05 \%)$. Less diversity was found in the essential oil from the orange leaves, in which 38 compounds were identified. Phenylpropanoids $(47.70 \pm 0.28 \%)$ were once again the predominant class, but the main constituent was the sesquiterpene $(E)$-caryophyllene $(41.72 \pm 1.65 \%)$, followed by eugenol $(20.99 \pm 0.21 \%)$ and croweacin $(9.76 \pm 0.14 \%)$.

Regarding the terpenoids found in the oils, the red flower variety had six-fold more monoterpenes than the orange variety. In contrast (as if a form of compensation in the production of these constituents), the amount of sesquiterpenes was twofold higher in the oil from the orange flowers. The major chemical constituents identified herein are found in both oils, varying only in terms of relative percentages. For example, $(E)$-asarone is the major constituent of the oil from the red flowers $(16.22 \pm 0.23 \%)$ and is found at a much lower percentage in the oil from the orange flowers $(1.50 \pm 0.00 \%)$. Likewise, $(E)$-caryophyllene is the major constituent of the oil from the orange flowers $(41.72 \pm 1.65 \%)$ 
Table 1. Percentage composition (\% $\%$ SD), specific rotation and yield of essential oils from red and orange flowers of Erythrina velutina

\begin{tabular}{|c|c|c|c|c|c|}
\hline Compounds & $\mathbf{R I}^{\mathbf{a}}$ & $\mathbf{R I}^{\mathbf{b}}$ & Red flowers & Orange flowers & Method of identification \\
\hline Yield $(\%) \pm \mathrm{SD}$ & & & $0.03 \pm 0.01$ & $0.07 \pm 0.00$ & \\
\hline$[\alpha]_{\mathrm{D}}^{25}\left(\mathrm{c} .=1, \mathrm{CH}_{2} \mathrm{Cl}_{2}\right)$ & & & $-27.4^{\circ}$ & $-18.0^{\circ}$ & \\
\hline (4Z)-Hexenol & 875 & 871 & $2.63 \pm 0.01$ & - & RI, MS \\
\hline Isopropyl-2-methyl Butyrate & 882 & 880 & $2.36 \pm 0.02$ & - & RI, MS \\
\hline$\alpha$-Thujene & 923 & 923 & $0.05 \pm 0.00$ & - & RI, MS \\
\hline$\alpha$-Pinene & 936 & 932 & $0.19 \pm 0.00$ & - & RI, MS, CI \\
\hline Sabinene & 972 & 969 & $0.22 \pm 0.00$ & - & RI, MS \\
\hline$\beta$-Pinene & 978 & 974 & $0.35 \pm 0.01$ & - & RI, MS \\
\hline Myrcene & 990 & 988 & $0.14 \pm 0.00$ & - & RI, MS, CI \\
\hline$\alpha$-Phellandrene & 1007 & 1002 & $0.08 \pm 0.00$ & - & RI, MS \\
\hline$\delta$-3-Carene & 1013 & 1008 & $0.17 \pm 0.00$ & - & RI, MS \\
\hline$o$-Cymene & 1024 & 1022 & $1.02 \pm 0.00$ & - & RI, MS \\
\hline Limonene & 1029 & 1024 & $2.22 \pm 0.03$ & - & RI, MS, CI \\
\hline$(E)$ - $\beta$-Ocimene & 1047 & 1044 & $0.10 \pm 0.40$ & - & RI, MS \\
\hline$\gamma$-Terpinene & 1058 & 1054 & $5.19 \pm 0.41$ & $0.50 \pm 0.01$ & RI, MS \\
\hline cis-Sabinene hydrate & 1067 & 1065 & $2.35 \pm 0.15$ & $0.20 \pm 0.00$ & RI, MS \\
\hline Terpineolene & 1089 & 1086 & $0.17 \pm 0.00$ & - & RI, MS, CI \\
\hline Linalool & 1100 & 1095 & $1.59 \pm 0.01$ & & RI, MS \\
\hline cis-Limonene oxide & 1133 & 1132 & $0.06 \pm 0.00$ & - & RI, MS \\
\hline Camphor & 1141 & 1141 & $0.33 \pm 0.00$ & - & RI, MS, CI \\
\hline Terpinen-4-ol & 1176 & 1174 & $1.35 \pm 0.01$ & $0.60 \pm 0.00$ & RI, MS \\
\hline$p$-Cymen-8-ol & 1183 & 1179 & $0.22 \pm 0.00$ & $0.55 \pm 0.00$ & RI, MS \\
\hline$\alpha$-Terpineol & 1190 & 1186 & $1.46 \pm 0.01$ & $1.26 \pm 0.02$ & RI, MS, CI \\
\hline Carvone & 1243 & 1239 & - & $0.10 \pm 0.00$ & RI, MS \\
\hline Thymol & 1287 & 1286 & - & $0.11 \pm 0.00$ & RI, MS, CI \\
\hline$p$-Cymen-7-ol & 1294 & 1289 & - & $0.33 \pm 0.00$ & RI, MS \\
\hline 3-Methoxy-acetophenone & 1295 & 1295 & $0.38 \pm 0.00$ & - & RI, MS \\
\hline Carvacrol & 1303 & 1298 & $0.68 \pm 0.00$ & $0.41 \pm 0.00$ & RI, MS, CI \\
\hline$p$-Vinyl-guaiacol & 1309 & 1309 & $0.14 \pm 0.00$ & $0.21 \pm 0.00$ & RI, MS \\
\hline Citronellic acid & 1313 & 1312 & - & $0.19 \pm 0.00$ & RI, MS \\
\hline$\delta$-Elemene & 1335 & 1335 & $0.28 \pm 0.00$ & $0.28 \pm 0.00$ & RI, MS \\
\hline$\alpha$-Terpinyl acetate & 1342 & 1341 & $0.10 \pm 0.00$ & - & RI, MS \\
\hline Eugenol & 1354 & 1354 & $6.05 \pm 0.64$ & $20.99 \pm 0.21$ & RI, MS, CI \\
\hline Decanoic acid & 1369 & 1364 & - & $0.10 \pm 0.00$ & RI, MS \\
\hline$\alpha$-Copaene & 1378 & 1374 & $0.18 \pm 0.00$ & $0.36 \pm 0.00$ & RI, MS \\
\hline$\beta$-Elemene & 1393 & 1389 & - & $0.03 \pm 0.00$ & RI, MS \\
\hline (E)-Caryophyllene & 1421 & 1417 & $12.22 \pm 0.11$ & $41.72 \pm 1.65$ & RI, MS, CI \\
\hline$\beta$-Copaene & 1431 & 1430 & - & $0.08 \pm 0.00$ & RI, MS \\
\hline (E)-Cinnamyl acetate & 1439 & 1440 & - & $0.18 \pm 0.00$ & RI, MS \\
\hline Myltayl-4(12)-ene & 1445 & 1445 & - & $0.12 \pm 0.00$ & RI, MS \\
\hline Croweacin & 1456 & 1455 & $1.62 \pm 0.02$ & $9.76 \pm 0.14$ & RI, MS \\
\hline Ishwarone & 1465 & 1465 & $0.34 \pm 0.00$ & $1.23 \pm 0.00$ & RI, MS \\
\hline$\gamma$-Muurolene & 1482 & 1478 & $1.38 \pm 0.02$ & $0.64 \pm 0.11$ & RI, MS \\
\hline Germacrene D & 1482 & 1481 & - & $0.95 \pm 0.01$ & RI, MS \\
\hline$\beta$-Selinene & 1487 & 1487 & - & $0.24 \pm 0.00$ & RI, MS \\
\hline cis- $\beta$-Guaiene & 1494 & 1492 & - & $0.27 \pm 0.00$ & RI, MS \\
\hline
\end{tabular}


Table 1. Percentage composition ( $\% \pm \mathrm{SD}$ ), specific rotation and yield of essential oils from red and orange flowers of Erythrina velutina (cont.)

\begin{tabular}{|c|c|c|c|c|c|}
\hline Compounds & $\mathbf{R I}^{\mathbf{a}}$ & $\mathbf{R I}^{\mathbf{b}}$ & Red flowers & Orange flowers & Method of identification \\
\hline Bicyclogermacrene & 1497 & 1500 & $0.44 \pm 0.00$ & $0.60 \pm 0.00$ & RI, MS \\
\hline$\alpha$-Muurolene & 1501 & 1500 & $0.31 \pm 0.00$ & $0.29 \pm 0.00$ & RI, MS \\
\hline Germacrene A & 1506 & 1505 & - & $0.07 \pm 0.12$ & RI, MS \\
\hline Eugenol acetate & 1520 & 1520 & $2.88 \pm 0.00$ & $2.48 \pm 0.00$ & RI, MS, CI \\
\hline Elemicin & 1551 & 1555 & $1.37 \pm 0.02$ & $1.82 \pm 0.00$ & RI, MS \\
\hline Geranyl butanoate & 1564 & 1562 & $1.56 \pm 0.00$ & - & RI, MS \\
\hline (Z)-Isoelemicin & 1569 & 1568 & $1.06 \pm 0.01$ & $1.59 \pm 0.02$ & RI, MS \\
\hline Caryophyllene oxide & 1582 & 1582 & $1.39 \pm 0.01$ & - & RI, MS, CI \\
\hline Guaiol & 1602 & 1600 & $0.36 \pm 0.00$ & - & RI, MS \\
\hline (Z)-Asarone & 1620 & 1616 & $5.99 \pm 0.05$ & $2.47 \pm 0.11$ & RI, MS, CI \\
\hline 1-epi-Cubebol & 1629 & 1627 & $0.33 \pm 0.00$ & - & RI, MS \\
\hline Exalatacin & 1654 & 1655 & $9.94 \pm 0.20$ & $2.17 \pm 0.01$ & RI, MS \\
\hline Valerianol & 1657 & 1656 & $2.87 \pm 0.01$ & - & RI, MS \\
\hline 7-epi- $\alpha$-Eudesmol & 1662 & 1662 & $2.04 \pm 0.01$ & - & RI, MS \\
\hline (E)-Asarone & 1673 & 1675 & $16.22 \pm 0.23$ & $1.50 \pm 0.00$ & RI, MS, CI \\
\hline Apiole & 1679 & 1678 & $4.29 \pm 0.60$ & $0.57 \pm 0.11$ & RI, MS, CI \\
\hline Total & & & $94.67 \pm 0.81$ & $95.97 \pm 1.93$ & \\
\hline Monoterpenes & & & $18.46 \pm 0.15$ & $3.77 \pm 0.00$ & \\
\hline Sesquiterpenes & & & $23.8 \pm 0.11$ & $44.40 \pm 1.60$ & \\
\hline Phenylpropanoids & & & $47.42 \pm 0.71$ & $47.70 \pm 0.28$ & \\
\hline Others & & & $4.99 \pm 0.02$ & $0.10 \pm 0.00$ & \\
\hline
\end{tabular}

$\mathrm{RI}^{\mathrm{a}}=$ retention indices calculated from retention times in relation to those of a series of $n$-alkanes in a $30 \mathrm{~m}$ DB- 5 capillary column. $\mathrm{RI}^{\mathrm{b}}=$ retention indices from the literature. $\mathrm{SD}=$ standard deviation, RI: retention index; MS: mass spectroscopy; CI: co-injection with authentic compounds. Method of identification: RI, MS and RI, MS, CI.

and is found at a lower percentage in the oil from the red flowers $(12.22 \pm 0.11 \%)$. Quantitative differences were also found for other constituents present in both oils, indicating quantitative variation in the chemical profile of the oils from the red and orange varieties. Among the 64 chemical constituents identified, 24 were found in both oils, demonstrating qualitative and quantitative differences in the chemical composition of the oils investigated.

These results were confirmed by PCA, which showed a clear separation of the two oils (Figure 1). Ninety-eight percent of the variability in the data was explained by the first $(\mathrm{PC} 1=92 \%)$ and second $(\mathrm{PC} 2=6 \%)$ components.

To the best of our knowledge, the only study on essential oils from the genus Erythrina in the literature describes the leaf oil from E. crista-galli ${ }^{19}$ and no similarities are found between it and the oils described herein. The oil from E. crista-galli had monoterpenes as the predominant chemical class $(70.2 \%)$, with linalool $(53.9 \%)$, spathulenol $(9.6 \%)$ and $\alpha$-terpineol $(8.4 \%)$ as the major constituents. Linalool and $\alpha$-terpineol were found in the present analyses only at

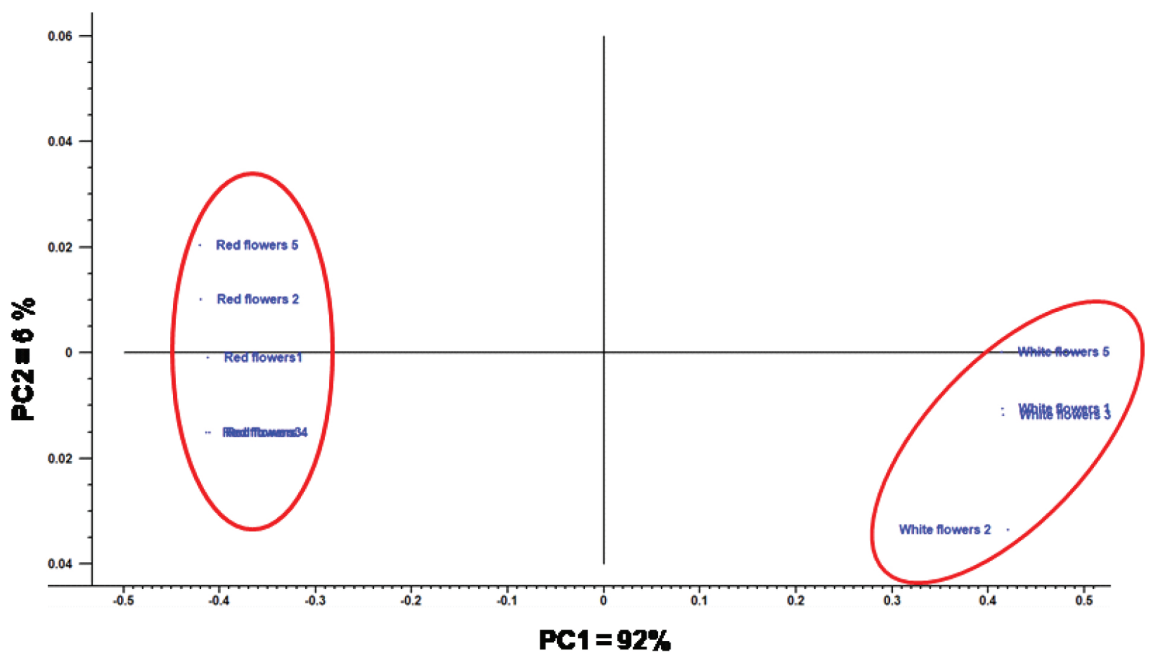

Figure 1. Principal component analysis of essential oils from Erythrina velutina 
low percentages $(1.59 \pm 0.01 \%$ and $1.46 \pm 0.01 \%$ in the red flower oil; $1.26 \pm 0.02 \%$ and $0.00 \pm 0.00 \%$ in the orange flower oil, respectively). Among the phenylpropanoids found in the red flower and orange flower oils from E. velutina, only eugenol was identified in the leaf oil from $E$. crista-galli (1.5\%). Moreover, $(E)$-caryophyllene was the major constituent of the orange flower oil from E. velutina and was not found in the oil from E. crista-galli.

The fatty acids from the red (red flower variety) and black (orange flower variety) seeds of E. velutina were analyzed by GC-MS (fatty acid chromatograms in Figure 2S, Supplementary Material). Table 2 displays the chemical compositions and yields of the fatty acids found in the red and black seeds.

A greater yield was achieved with the red seeds $(11.93 \pm 0.60 \%)$, which is similar to the yield described by $\mathrm{RaO}^{20}$ for the white seeds of the white variety of E. indica (about $12 \%$ fatty acids).

A total of 13 fatty acids were identified in the two seed varieties, representing $91.17 \pm 1.40 \%$ of the oil from the red seeds

Table 2. Relative composition ( $\% \pm \mathrm{SD}$ ) and yield of fatty acids from red and black Erythrina velutina seeds

\begin{tabular}{lcc}
\hline Fatty acids & Red & Black \\
\hline Yield $(\%) \pm$ SD & $11.93 \pm 0.60$ & $7.97 \pm 0.53$ \\
Myristic acid (C14:0) & $1.57 \pm 0.01$ & $1.99 \pm 0.02$ \\
Palmitic acid (C16:0) & $15.39 \pm 0.16$ & $12.33 \pm 0.41$ \\
Palmitoleic acid (C16:1) & $3.78 \pm 0.02$ & $1.09 \pm 0.00$ \\
Stearic acid (C18:0) & $0.46 \pm 0.00$ & $1.28 \pm 0.12$ \\
Oleic acid (C18:1) & $41.56 \pm 1.33$ & $46.12 \pm 1.90$ \\
Linoleic acid (C18:2) & $6.13 \pm 0.41$ & $10.58 \pm 0.52$ \\
Linolenic acid (C18:3) & $0.24 \pm 0.00$ & $0.32 \pm 0.01$ \\
Behenic acid (C22:0) & $9.95 \pm 0.14$ & $12.10 \pm 0.42$ \\
Eicosenoic acid (C20:1) & $5.44 \pm 0.09$ & $4.43 \pm 0.08$ \\
Eicosadienoic acid (C20:2) & $4.21 \pm 0.12$ & $3.88 \pm 0.12$ \\
Dihomo- $\gamma$-linolenic acid (C20:3) & $0.10 \pm 0.01$ & $0.19 \pm 0.05$ \\
Erucic acid (C22:1) & $2.16 \pm 0.05$ & $0.14 \pm 0.01$ \\
Docosadienoic acid (C22:2) & $0.22 \pm 0.00$ & $1.10 \pm 0.04$ \\
\hline Total Saturated fatty acids & $28.36 \pm 0.14$ & $27.60 \pm 0.09$ \\
Total monounsaturated fatty acids & $52.94 \pm 1.44$ & $51.78 \pm 0.38$ \\
Total polyunsaturated fatty acids & $9.90 \pm 0.16$ & $16.07 \pm 1.94$ \\
\hline Total & $91.20 \pm 1.40$ & $95.55 \pm 1.76$ \\
\hline SD 5 (C) & & \\
\hline
\end{tabular}

$\mathrm{SD}=$ standard deviation. and $95.55 \pm 1.76 \%$ of the oil from the black seeds. The oils from both colors of seeds were characterized by long-chain fatty acids ranging from 14 to 22 carbon atoms, containing saturated fatty acids $(28.36 \pm 0.14 \%$ for red seeds and $27.60 \pm 0.09 \%$ for black seeds), monounsaturated fatty acids (52.94 $\pm 1.44 \%$ for red seeds and $51.78 \pm 0.38 \%$ for black seeds) and polyunsaturated fatty acids $(9.90 \pm 0.16 \%$ for red seeds and $16.07 \pm 1.94 \%$ for black seeds). The fatty acids characterized in the red and black seeds have a similar chemical profile, varying only in the relative percentages. For example, oleic acid (C18:1) is the major component of both seeds, with a significant difference in the percentage $(46.12 \pm 1.90 \%$ for black seeds and $41.56 \pm 1.33 \%$ for red seeds). Other significant differences were found for palmitic acid (C16:0) (15.39 \pm 0.36 and $12.33 \pm 0.41 \%$ for red and black seeds, respectively), behenic acid $(\mathrm{C} 22: 0)(9.95 \pm 0.14 \%$ and $12.10 \pm 0.42 \%)$ and linoleic acid $(\mathrm{C} 18: 2)$ $(6.13 \pm 0.41 \%$ and $10.58 \pm 0.52 \%)$.

The data on the fatty acid composition of the E. velutina seeds in the present study are similar to those reported by Mayworm et $a l .{ }^{16}$ for a sample collected in the state of Bahia, Brazil, with regard to the major constituents $(51.0 \%$ oleic acid, $14.8 \%$ linoleic acid, $10.7 \%$ behenic acid and $10.0 \%$ palmitic acid). However, arachidic acid $(2.8 \%)$ and lignoceric acid $(2.6 \%)$ described in the sample from Bahia were not found in the present study.

The similarities among the fatty acids in the black and red seeds reported in this study from samples collected on the island of Fernando de Noronha and a sample collected in the state of Bahia were confirmed by hierarchical cluster analysis (HCA) and principal component analysis (PCA).

Figure 1 presents the HCA of the fatty acids identified in black and red seeds collected from Fernando de Noronha as well as data compiled from the literature on fatty acids identified in E. velutina from Bahia and other congeners from different regions of the world: E. variegata, E. lithosperna, E. arborescens, E. stricta, E. indica 1, E. indica 2, E. indica 3, E. speciosa, E. suberosa and E. americana. ${ }^{16}$

HCA revealed $93.8 \%$ similarity among the fatty acids found in the black and red seeds from E. velutina collected on the island of Fernando de Noronha and reds seeds from E. velutina collected in the state of Bahia (Figure 2). This similarity was supported by the PCA (Figure 3), in which the first two components explained $79 \%$ of the variation in the data $(\mathrm{PC} 1=57 \%$ and $\mathrm{PC} 2=22 \%)$. The graph shows the formation of a distinct group formed by the red and black seeds in the present study and the seeds from E. velutina collected in the state of Bahia.

These results show that, despite differences in the chemical composition of the essential oils from the red and orange flowers

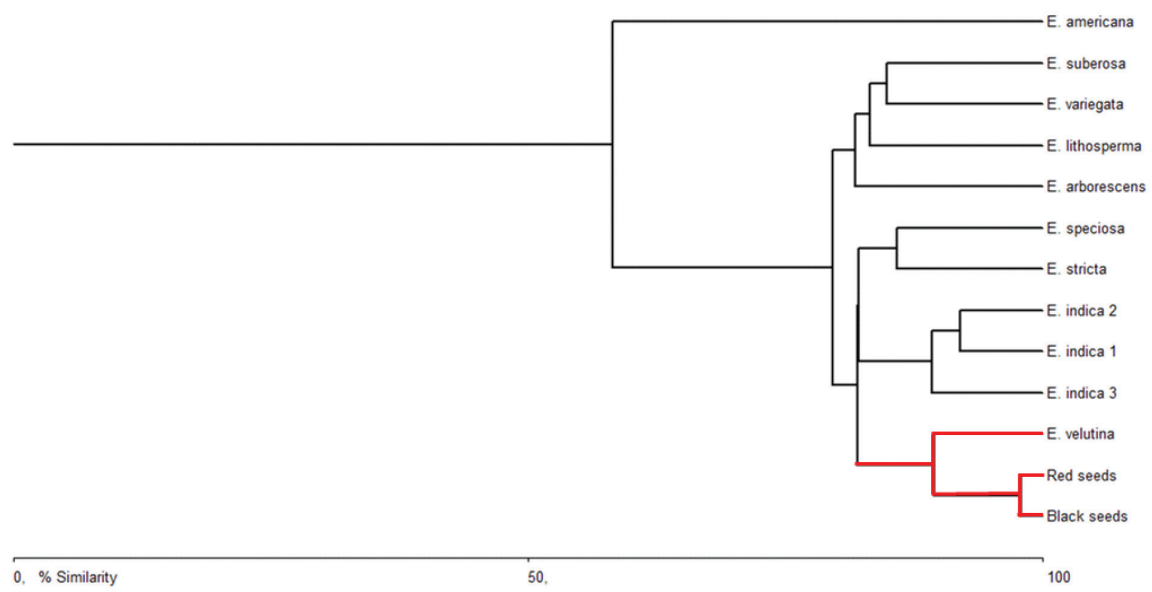

Figure 2. Hierarchical cluster analysis of similarity in fatty acid profile among species of Erythrina 


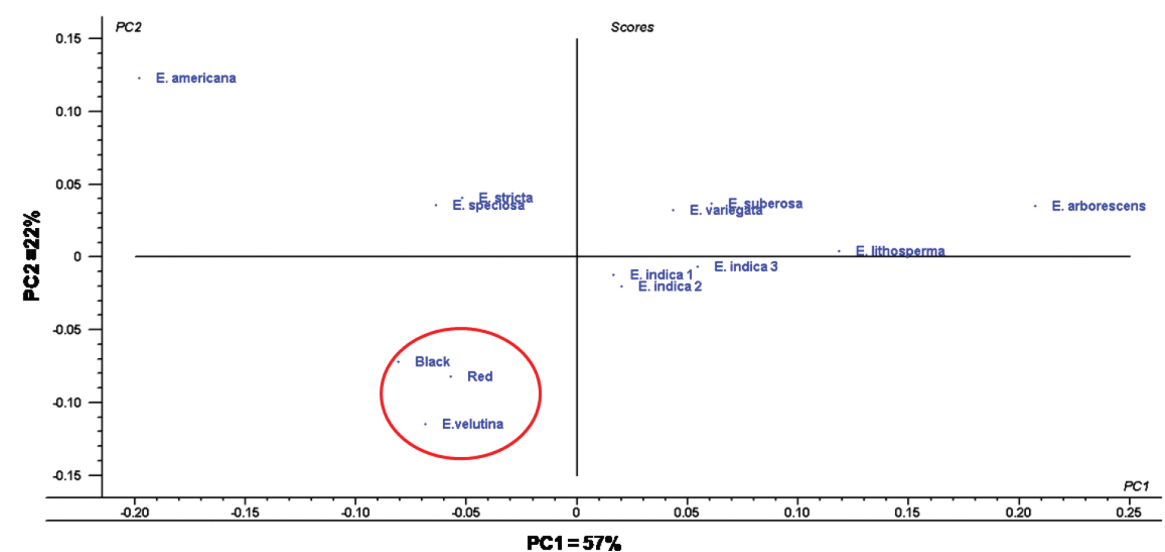

Figure 3. Principal component analysis of fatty acids in seeds from species of Erythrina

of E. velutina, the chemical composition of the fatty acids in the black and red seeds of these plants did not differ. Therefore, despite the difference in the color of the seeds, the samples have the same chemotype.

\section{CONCLUSION}

This is the first study on the chemical composition of essential oils from the flowers of E. velutina. The oils from the orange and red flowers exhibit significant qualitative and quantitative differences in the chemical profile, which were confirmed by principal component analysis. Although phenylpropanoids are the predominant chemical class in both oils, $(E)$-caryophyllene is the major constituent in the orange flower oil, whereas $(E)$-asarone is the major constituent of the red flower oil.

Oleic acid, palmitic acid and behenic acid were the main fatty acids found in the red and black seeds of E. velutina. PCA and HCA confirmed a high degree of similarity in the fatty acid profile of the two chromatic variations of seeds.

\section{SUPPLEMENTARY MATERIAL}

Figures $1 \mathrm{~S}$ and $2 \mathrm{~S}$ are available at http://quimicanova.sbq.org.br as a pdf file (free access).

\section{ACKNOWLEDGMENTS}

The authors are grateful to the Brazilian fostering agencies Fundação de Amparo à Ciência e Tecnologia do Estado de Pernambuco (FACEPE), Conselho Nacional de Desenvolvimento Científico e Tecnológico $(\mathrm{CNPq})$ and Coordenação de Aperfeiçoamento de Pessoal de Nivel Superior for awarding a grant (CAPES - Proc. \# IBPG-09845.01/10), productivity scholarship (CNPq, \# 312277/2013-0) and funding for this study (CNPq \# 403162/203-0; FACEPE \# APQ1008-1.06/15; APQ-0476-1.06/14; APQ-08601.06/16).

\section{REFERENCES}

1. Schrire, B. D. In Legumes of the world; Lewis, G., Schrire, B. D., Mackinder, B., Lock, M., eds.; Royal Botanic Gardens: Kew, 2005, pp. 393-431.

2. http://floradobrasil.jbrj.gov.br/jabot/floradobrasil/FB22965, accessed in October 2018

3. Lorenzi, H.; Árvores brasileiras: Manual de Identificação e Cultivo de Plantas arbóreas nativas do Brasil, Editora Plantarum: São Paulo, 1992.

4. Agra, M. F.; Silva, K. N.; Basílio, I. J. L. D.; França, P. F.; BarbosaFilho, J. M.; Rev. Bras. Farmacogn. 2008, 18, 472.
5. Neill, D. A. In Erythrina in the New and Old Worlds; Westley, S. B., Powell, M. H., eds.; Nitrogen Fixing Tree Research Reports: Hawaii, 1993, cap. 1.

6. Lorenzi, H.; Matos, F. J. A.; Plantas Medicinais no Brasil: Nativas e Exóticas, $2^{\text {nd }}$ ed., Nova Odessa/Plantarum: São Paulo, 2008.

7. Ridley, H. N.; Bot. J. Linn. Soc. 1890, 27, 95.

8. Krukoff, B. A.; Brittonia 1939, 3, 205

9. Martins, M. V.; Tese de Doutorado, Universidade estadual de Campinas, Brasil, 2014.

10. Da Cunha, E. V. L.; Dias, C.; Barbosa-Filho, J. M.; Gray, A. I.; Phytochemistry 1996, 43, 1371.

11. Rabelo, L. A.; Agra, M. F.; Cunha, E. V. L.; Silva, M. S.; Barbosa-Filho. J. M.; Biochem. Syst. Ecol. 2001, 29, 543.

12. Fernandes, A. M. A. P.; Khatib, E. S.; Cunha, I. B. S.; Porcari, A. M.; Eberlin, M. N.; Silva, M. J.; Silva, P. R.; Cunha, V. S.; Daroda, R. J.; Alberici, R. M.; Energy Fuel 2015, 29, 3096.

13. Van D. L. H.; Kratz, P. H.; J. Chromatogr. A 1963, 11, 463.

14. Johnson, S.; NIST Standard Reference Database 1A: Mass Spectral Library, version 14; National Institute of Standards and Technology: Gaithersburg, MD, 2016.

15. Adams, R. P.; Identification of Essential Oil Components by Gas Chromatography/ Quadrupole Mass Espectroscopy, $4^{\text {th }}$ ed., Allured Publishing Corporation: Carol Stream, 2007.

16. Samanta, T. D.; Laskar, S.; Biosci. Biotech. Res. Asia. 2013, 10, 433; Mayworm, M. A. S.; Nascimento, A. S.; Salatino, A.; Rev. Bras. Bot. 1998, 21, 961; Tandon, S. P.; Tiwari, K. Prasad.; Gupta, A. P.; Indian Oil and Soap J. 1969, 34, 151; Singh, H.; Chawla, A. S.; Jindal, A. K.; Subbaram, M. R.; Achaya, K. T.; Indian J. Technol. 1972, 10, 115; Amir, F.; Wan, S. Y.; Yen, C. K.; Eur. J. Chem. 2011, 2, 561; Pugalenthi, M.; Vadivel, V.; Gurumoorthi, P.; Janardhanan, K.; Trop. Subtrop. Agroecosyst. 2004, 4, 107; 22. Tresina, P. S.; Mohan, V. R.; Trop. Subtrop. Agroecosyst. 2012, 15, 539; Mello, J. I. O.; Barbedo, C. J.; Salatino, A.; Figueiredo-Ribeiro, R. C. L.; Braz. Arch. Biol. Technol. 2010, 53, 889; Joshi, R.; Garg, B. D.; J. Sci. Res. 1981, 3, 11; Giral, F.; Mariel, R.; Cienc. Mex. 1959, 19, 27.

17. McAlece, N.; Gage, J. D. G.; Lambshead, P. J. D.; Paterson, G. L. J.; BioDiversity Professional statistics analysis software, Scottish Association for Marine Science and the Natural History Museum, London, 1997.

18. Unscrambler ${ }^{\circledR}$ software version 9.5, CAMO Process AS, Norway, 19962010.

19. Lamarque, A. L.; Damian M.; Maestri1, J. A. Z.; Nelson R. G.; Flavour Fragr. J. 1998, 13, 266.

20. Rao, J. V. P. R.; Curr. Sci. 1945, 14, 198 